\title{
Cyclones and Societies in the Mascarene Islands 17th-20th Centuries
}

\author{
Emmanuel Garnier ${ }^{1,2,3}$, Jérémy Desarthe ${ }^{3,4}$ \\ ${ }^{1}$ Churchill College, University of Cambridge, Cambridge, UK \\ ${ }^{2}$ Institut Universitaire de France, Paris, France \\ ${ }^{3}$ Centre de Recherche d'Histoire Quantitative (UMR CNRS), University of Caen, Caen, France \\ ${ }^{4}$ Institute for Sustainable Development and International Relations, Sciences Po, Paris, France \\ Email: eg398@cam.ac.uk
}

Received December 16, 2012; revised January 15, 2013; accepted January 22, 2013

\begin{abstract}
The recent IPCC-SREX report focuses on the impact of extreme weather events on societies and underlines the absence of reliable data to assert a solid link between them and the current global climate change. Thanks to the unpublished materials that are contained in historic archives, this article suggests studying the cyclones which affected the Mascarene islands between 1654 and 2007 and which supply us with a catalog of hitherto unpublished events. Inspired by the Simpson-Saffir hurricanes Wind Scale, the research proposes a relative evaluation of the extremes of the region. It underlines the big fluctuations in the last three centuries and partially answers the current debate on the reliability of the data in relation to hurricanes and their link with the contemporary climate. The available archives show that this type of meteorological event has occurred frequently during the relevant historical period and that for that reason, has given rise to original strategies of adaptation on the part of the societies affected. The results presented here constitute new and reliable data which could make an important contribution to the decision-makers and to climatologists trying to design strategies which the populations of small islands facing the climatic hazards of the future will have to adopt.
\end{abstract}

Keywords: History; Archives; Cyclones; Mascarene Islands; Society; Risk; Vulnerability; Adaptation; Resilience

\section{Introduction}

The very recent SREX [1] report points out that the major part of available historical data relating to hurricanes is limited to a very recent and precise period which in the case of the tropical cyclones generally includes from the middle of the 20th century to the present. In addition to the limited period of records, the uncertainties in the historical tropical data and the extent of tropical variability don't presently allow for the detection of any clear trends in tropical hurricane activity that can be attributed to Global Climate Change. In the face of these uncertainties, the SREX report thus prefers to remind us that it is very difficult and careless to predict too rapid an increase in the frequency of the strongest storms in the coming decades. It therefore concludes that there is no clear signal between these extreme events and SRES A1B Warming scenario.

In response to this assessment a recent piece of research tried to remedy these gaps by suggesting reconstructing an older historic series concerning the cyclonic activity in the southwest of the United States [2]. From the data supplied by six tide gauges of the region since 1923 , in other words for a period longer than that covered by satellites, this work tries to produce a series based on the intensity of the storm surge. Very new, this research shows clearly, while not proving the link between global climate change and the cyclonic activity, that there is indeed a difference in the frequency of these events between cold years and the warm years. More interesting still, it reveals that there is also a sustainable increase of the number of cyclones during the 20th century, at least since 1923.

Nevertheless, it is possible to widen considerably the chronology of storms and surge storm to propose a much more historic approach of the coastal extreme events [3] [4]. Nevertheless, such an objective requires opening the subject up to the involvement of the social sciences and more particularly of history. Indeed, this enables one to offer to the climatologists and to the climate modelers new original and unpublished data materials extracted from rather homogeneous and at the same time plentiful archives. Better still, the archives of the historian offer the climate scientists the opportunity to reconstruct very long series of events about 300 or 500 years according to the regions of the world. In this paper, we suggest studying the historic example of the Mascarene Islands be- 
tween the middle of the 17 th a century and 2007 according to two generally new approaches. They study successively the frequency and the severity of cyclones in this part of Indian Ocean as well as the impact which they had on the island societies.

More than the mere reconstruction of series of events to the exclusive service of a more reliable modeling, the major stake in the interdisciplinary approach lies from now on in a better knowledge of the impacts to which the populations were exposed and the strength of the strategies which they were able to elaborate to survive. In this respect, the SREX report insists without ambiguity on the strategic character of this aspect of the climate change from now on. The systematic use of the terms of risk, exposure, vulnerability and sustainability is an obvious proof. It shows that the social dimension has become henceforth a strategic objective of the IPCC which concluded that we could not confine themselves only to mathematical projections of the climate which are often badly received by public opinion. Yet, the history of the climate can exactly enlighten the human reality of these extreme climate events of the past and serve as a tool of mediation between the scientific community and the citizens.

\section{The Contexts of the Research}

\subsection{Study Area and Risk of Hurricane}

The archipelago of Mascarenes is situated in the southwest of Indian Ocean, east of Madagascar, between the 19th south parallel and the tropic of Capricorn (Figure 1). It groups the Reunion Island, Mauritius, island Rogriguez, islands Agalega and Cargados. These rather distant islands have however common points: they are of volcanic origin and they regularly undergo hurricanes of strong intensity which increase considerably their vulnerability during the season of cyclones between December and March.

Paradoxically, the bibliography dedicated to this risk in the region is very poor. Generally, the north part of Indian Ocean held the interest of the researchers more. The variation of the activity of the tropical cyclones in the South of Indian Ocean is today difficult to understand and only Chang-Hoi et al. tried to make it from a comparison with the El-Nino-Southern Oscillation and the oscillation of Madden-Julian Oscillation [5]. Hoarau et al. were very interested recently in the variability of the most severe tropical cyclones (category 3 - 5) for period 1980-2009 [6]. They showed that the ten-year distribution of cyclones did not reveal clear trend of an increase of the cyclones of category 3 - 5 during the last 30 years, in spite of a doubling of the cyclonic activity with regard to 1980 s and 2000. In conclusion, the authors of the study underline the importance of a more historic ap-

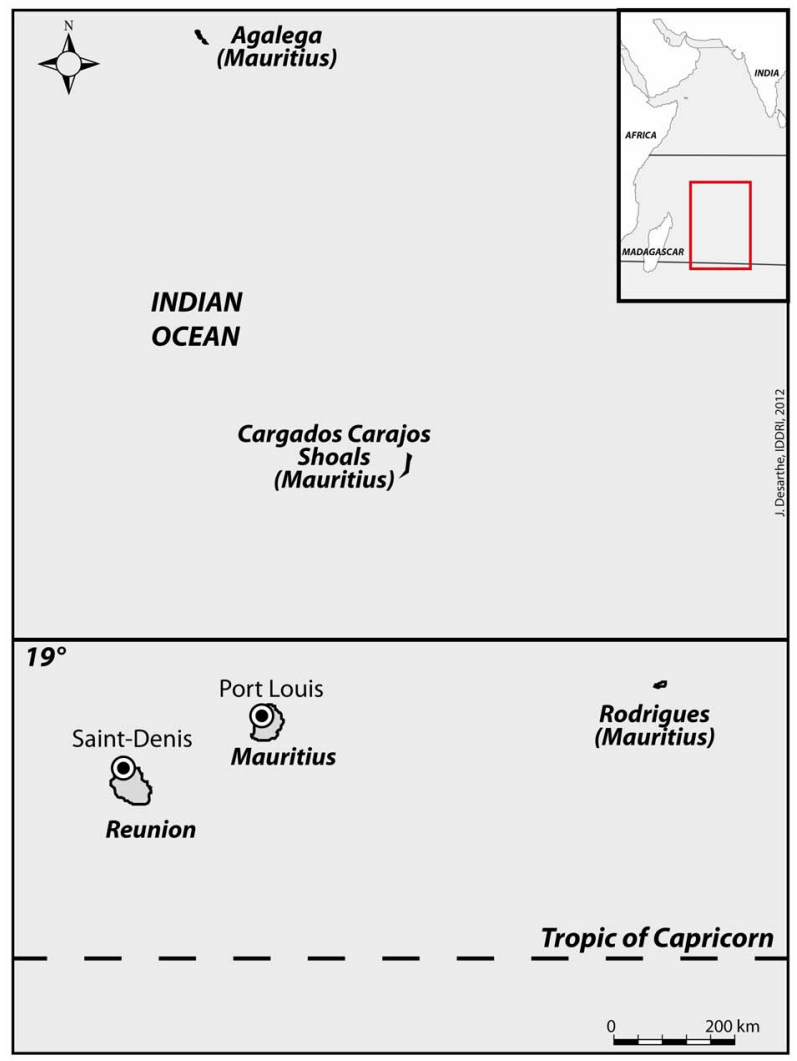

Figure 1. Map of the Mascarenes.

proach. They insist on the weakness of their results because of the absence of older data which would have allowed them to discern natural cycles in the decadal variations of intense cyclone activity.

The historic available data for the researchers interested in the tropical cyclones are extremely limited and very scattered [7]. NOAA's National Climatic Data Center (NCDC), in concert with the World Data Center (NCDC) has developed a comprehensive dataset through the collection of global tropical cyclone best-track: the International Best Track Archive for Climate Stewardship (IBTrACS). The major goal of the IBTrACS dataset was to provide the first publicly available centralized repository of global tropical cyclone best-track data from different agencies. The inventory of cyclones and storms per decade so obtained indicates clearly that the majority of the available data only begins in the 1950s. For the South of Indian Ocean, the most reliable and plentiful historic information appears only by 1880 .

\subsection{The Historical Material}

The volume and the quality of the available archives for the South of Indian Ocean result directly from an original political history based on the major strategic interest that the Mascarene Islands represented for the British and French powers. 


\subsubsection{A Colonial and Slave History}

The archipelago of Mascareignes was known by Arabs from the 10th century but it is the Portuguese sailor Pedro de Mascarenhas who made it known in Europe in the first half of the 16th century. The first real colonization of the island begins in 1638 with the installation of the Dutch people. Struck by a very violent hurricane in February 1695, the colony was not able to recover and finally, the Governor decided to leave in 1706 by evacuating about 200 people. In 1715, the French replaced the Dutch until 1810, the year of the British conquest whose dominion did not end until 1968 [8]. Throughout the French period, this island was called "Ile de France". The nearby island of Reunion was occupied by the French in 1665 and took the name "Ile Bourbon" until 1806. It remained under French rule until today except for a very short period of British occupation between 1810 and 1815, during the Napoleonic Wars.

Now under the exclusive dominion of the King of France, the archipelago was entrusted to the French East India Company to develop trade between the Kingdom and colonies overseas. From 1720, Reunion and Mauritius were organized settlements designed to produce mainly coffee and sugar for the metropolis. The economic system thus created was based on the use of slave labor from the Senegal Coastline, East Africa and Madagascar. Almost independent, the Company created a business empire consisting of counters in India (Chandernagore, Pondicherry, Mahe) in the Mascarene Islands, on the Persian Gulf, Burma and Indonesia. To ensure its dominance, the company got a government, an army and a navy controlled by a governor [9]. This bureaucracy finally changed little after the French Revolution of 1789, and explains the richness and quality of records available for the study of hurricanes.

\subsubsection{Archives and Their Content}

For convenience, we distinguish the pre-revolutionary period (before 1789) the contemporary period between 1789 and today. It is important to remember that the period after 1789 saw a significant political alternation between the monarchy (1815-1848) and the French Republic (1848-present).

Before 1789, the archives for studying hurricanes mainly concern the correspondence of Directors of the East India Company between 1700 and 1789. Of course, these sets of archives do not contain files specifically devoted to hurricanes and must therefore make very long and random analysis in this voluminous stock of archives. Primarily devoted to the management of maritime trade and the plantation economy, these records regularly mention extreme weather events and the main threat is hurricanes. In fact, the winds usually accompanied by heavy rainfall often have an impact on the fleet at anchor in the ports and on the plantations where they can cause the death of many slaves, destruction of crops and sugar refineries. Such damage had an immediate impact on the fragile economy of the islands and it is not uncommon that famine and disease followed after a hurricane. The examples below give an idea of the extent and nature of damage caused by these events.

Letter of the governor of the Ile-de-France (Mauritius) of the April 1st, 1718:

The hurricane was particularly violent. The harvest of coffee was almost lost. The hurricane provoked the filling of a river with pebbles pulled by rains and torrents. This filling transformed lands near the "river of Pebbles" into a desert.

Letter of the governor of the Ile-de-France (Mauritius) of March 8th, 1743:

We had a hurricane on March 8th. The big rashness of the wind lasted only from ten o'clock in the evening till two o'clock at night. Several vessels ran aground in the port because of very high waves which reached the store of the port. The harvest was almost completely destroyed, in particular the corn, the potatoes and the sugar canes. On the other hand, the rice and the manioc were protected. As soon as our port (Port Louis) will be repaired, I shall send to you by boat of the peas of the Cape (South Africa) and the beans which you can distribute in the poorest and to the blacks.

After 1789, the available material becomes even more precise about hurricanes and about their effects. On the British side, the archives of Colonial Office and of Secretary of State for the Colonies situated today in the national archives (Kew) supply extremely detailed reports on hurricanes having struck Mauritius fin the 19th and 20th centuries. In a rather systematic way, these documents give climatic information resulting from Meteorological Offices of the island. They concern the chronology and the meteorological parameters (temperature, pressure, winds) of the event. Then, the authors describe exactly the nature of the damage caused by the extreme event by enumerating buildings, trees, infrastructures as well as crops. At the same time, the cost of the damage is estimated because it justifies the measures of assistance taken by the government in London. These English archives focus on the consequences that cyclones can have on the Mauritius's big source of wealth: the sugar production. The economic stakes explain the publication of numerous governmental reports and planters' labor unions in the Mauritius's agricultural Bulletin. The administrative archives can be completed by the colonial press of period, in particular The Mercury, The Brisbane Courrier and The Straits Times Weekly Issue. Besides meteorological and social data (deaths, destruction), newspapers get the first photos during the big hurricane of 1892 .

For La Réunion, archives also become stronger with 
the development of the republican centralist model which is translated by the increase of the administrations. The services of the governor, the Conseil Général and the Farmers' association guarantee the historian an excellent quality of the information. So from 1820 the archives of the government of the colony of La Réunion contain files specially dedicated to hurricanes. We find in particular the very precise statements of the colonial gendarmes (French military policemen) whose barracks were distributed throughout the whole island. They supply from now on a state of the disaster for every part of La Réunion, which facilitates the evaluation of the severity of the hurricane. From the point of view of the vulnerability of territories, the geographical precision of these reportsauthorizes a cartography of zones destroyed on the scale of a street or field. Finally, let us add inquiries made by the state employees of the forest administration about trees broken or uprooted by winds. This silvicultural information is a very precious resource which allows us to evaluate the severity of these historic events today even without information from meteorological instruments or also where events may have been totally underestimated by the various Meteorological Offices of Mascareignes (Météo-France and Mauritius Meteorological Services) whose catalogs of events begin in the first half of the 20th century.

\section{Reconstruction of Cyclones 17th-20th Centuries}

\subsection{Method}

The archives can therefore establish a longer time series than those currently offered by the meteorological services of the Indian Ocean that can't consider exploring the historical archives. Historical material involves work that only professional climate historians can achieve due to their mastery of the archives, the historical method and technical knowledge in fields such as palaeography. However, the results obtained from the archives can only be useful to climatologists and meteorologists if the historian is able to translate his "social" data in more quantitative data. Indeed, archives supply information on the extreme events only according to the damage which they cause to societies and it is necessary to wait for 1850 s to find finally data of instrumental nature (strength and orientation of winds, barometric pressure). And yet, nowadays, the meteorologists estimate the severity of hurricanes in order to compare them more easily according to their destructive power. To achieve this, they use the Simpson-Saffir hurricanes Wind Scale (SSHWS) which gives an estimation of the damage engendered by hurricanes. Set up in 1969 by Herbert Saffir, a consulting engineer, and Bob Simpson, Director of the National Hurricane Center, this scale provides examples of the types of damage caused by winds [10] and classifies hurricanes into five categories [11]. Subsequently, it has been improved by adding other additional parameters such as storm surge and floods. If the scale does not give full satisfaction to assess a hurricane today, however, it is particularly well suited to the material historical sources mentioned above. We therefore decided to resume headings modifying to adapt to historical descriptions (Appendix 1). The criteria to estimate the hurricanes of the past can be divided into 12 criteria:

- Meteorological details;

- People, livestock;

- Infrastructure;

- Buildings (slave huts, colonial houses, barracks, stone churchs, stone stores and Governor's Palace);

- Plantations;

- State of the sea;

- Ships;

- Landscape;

- Trees;

- Surge;

- Power and water;

- Social and economic consequences.

Thus organized, the "historic" SSHWS assigns to each event an index between 1 and 5. Nevertheless, the method has a certain limit when it comes to record events of lesser intensity between categories 1 and 3 of the scale. Indeed, the historical data available for the 17 th and 18 th centuries mainly provide social and economic information, that is to say information that provide information on the damage suffered by the island societies. The traces left by hurricanes in the archives thus mainly interested the most severe events that can be classified among categories 3 - 5 scale. Consequently, the approach taken in this work struggles to register extreme events located in the low or medium frequency severity before 1850 . After this date, the instrumental quality archives (weather reports and instrumental data) significantly refines the interpretation and allows to better take into account the low-intensity hurricanes (category 1 - 3). In addition, sometimes a hurricane archive relate to a specific date without providing sufficient information to place on the scale. In this case, we have chosen to assign it an index -1 , so it appears on the chronological chart but without estimation of its severity.

\subsection{Frequency and Severity}

We have found 89 cyclones in the archives between 1656 and 2007 for the Mascarene archipelago. They show very strong fluctuations according to the century (Table $\mathbf{1}$ and Figure 2). The distribution of hurricanes over the last three centuries displays strong contrasts. Weakness during the 17 th century is very likely due to incomplete re- 


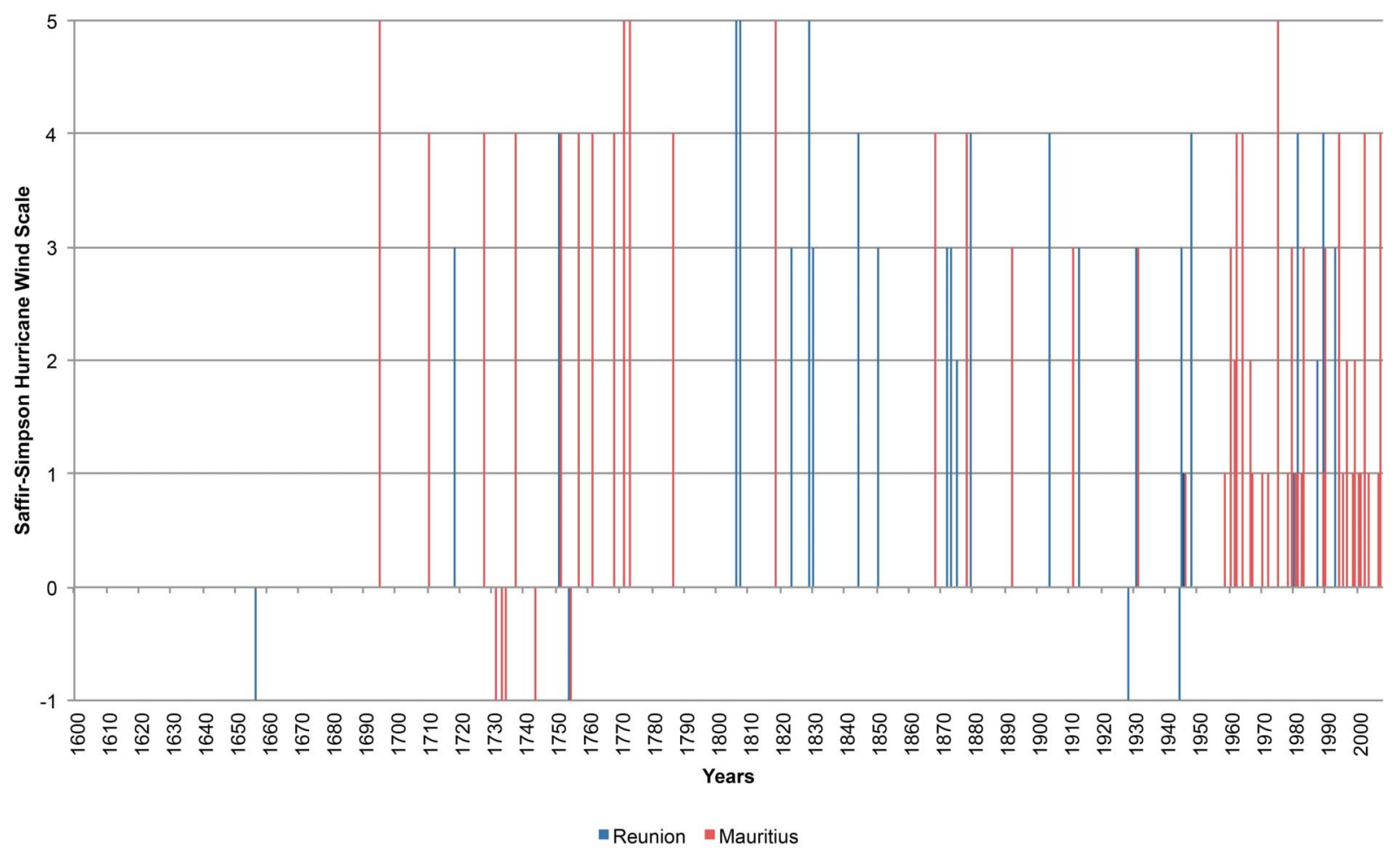

Figure 2. Chronology and severity (according to the SSHWS) cyclones in Mascarene islands between 1656 and 2007. The blue columns correspond to the events of La Réunion and the red to those of Mauritius. Source: see manuscript sources.

Table 1. Distribution by century and by category of cyclones in the Mascarene Islands.

\begin{tabular}{cccccccc}
\hline Category & -1 & 1 & 2 & 3 & 4 & 5 & Total \\
\hline $1600-1699$ & 1 & & & & & 1 & 2 \\
$1700-1799$ & 7 & & & 1 & 9 & 3 & 20 \\
$1800-1899$ & & & 1 & 6 & 5 & 5 & 17 \\
$1900-1999$ & 1 & 16 & 7 & 9 & 9 & 1 & 43 \\
$2000-2007$ & & 4 & & 1 & 2 & & 7 \\
Total & 9 & 20 & 8 & 17 & 25 & 10 & 89 \\
\hline
\end{tabular}

cords and the beginning of the European colonization of the region. For the subsequent period, the results show that the 18th century was more frequently affected by the extremes than the 19th century. However, the observation of the entire series clearly shows a rising trend during the 20th century, which displays a score of $43 \mathrm{cy}-$ clones, the little less than half of the total. The clear domination of the 20th century cannot be explained by a better recording of extremes in the 20th century than in the archives from the period 1700-1900.

Besides the fact of confirming the increase in the number of cyclones in the 20th century, Figure 3 specifies the chronology of this development. Years 1900-1959 seem rather sparse whereas a turning point occurs in 1960 with an almost continuous increase of the number of cyclones till the end of the millennium and a peak of frequency during decade 1980 . However, the increase in the number of the events does not seem to be mirrored by an escalation of their severity estimated according to the SSHWS.

On the contrary, the Figure 4 which presents the cycles of 50 years shows clearly that the period 1950-1999 is almost exempt from hazards of category 5 (one event) while the category 1 offers near half of the number. We can thus conclude that the increase of cyclones in Mascarene islands is not mirrored by an escalation of their severity. On the other hand, we can think that this greater frequency, of low or average intensity, will probably increase the vulnerability of the island societies of the region in the next decade.

\section{Vulnerability and Adaptation of Society of the Mascarene in the Past}

IPCC-SREX-report identifies small islands in Pacific, Indian and Atlantic as the areas most at risk of climate extremes. It considers that the main climate models give the same signal: the future risk increased. The report addresses the issue from a strategic perspective, since it speaks of the challenge of adapting and lists the vulnerabilities of these islands whose future development is directly threatened. However, it does not seem able to truly assess the particular risk to the Indian Ocean, for 


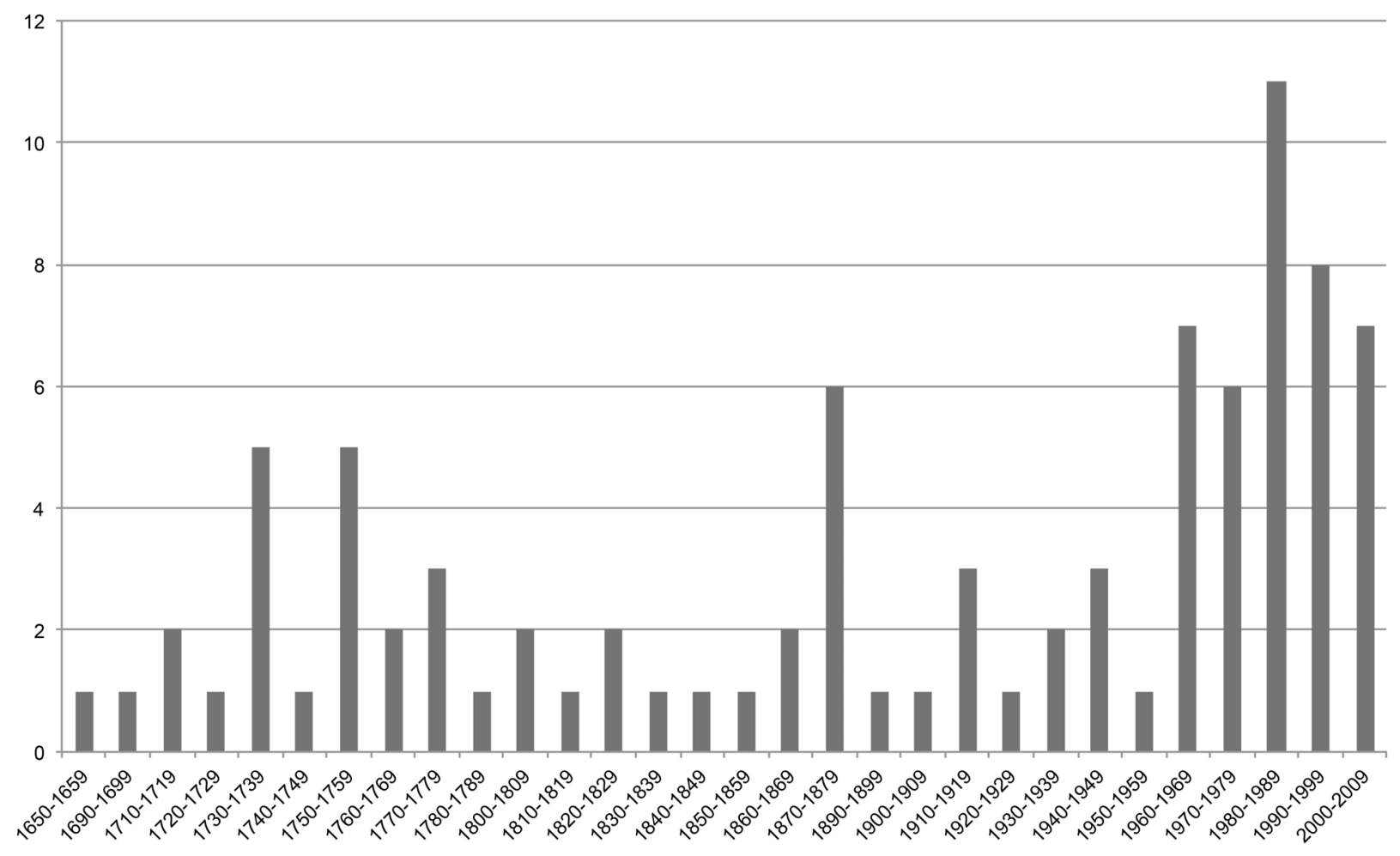

Figure 3. Distribution of cyclones by ten-year period.

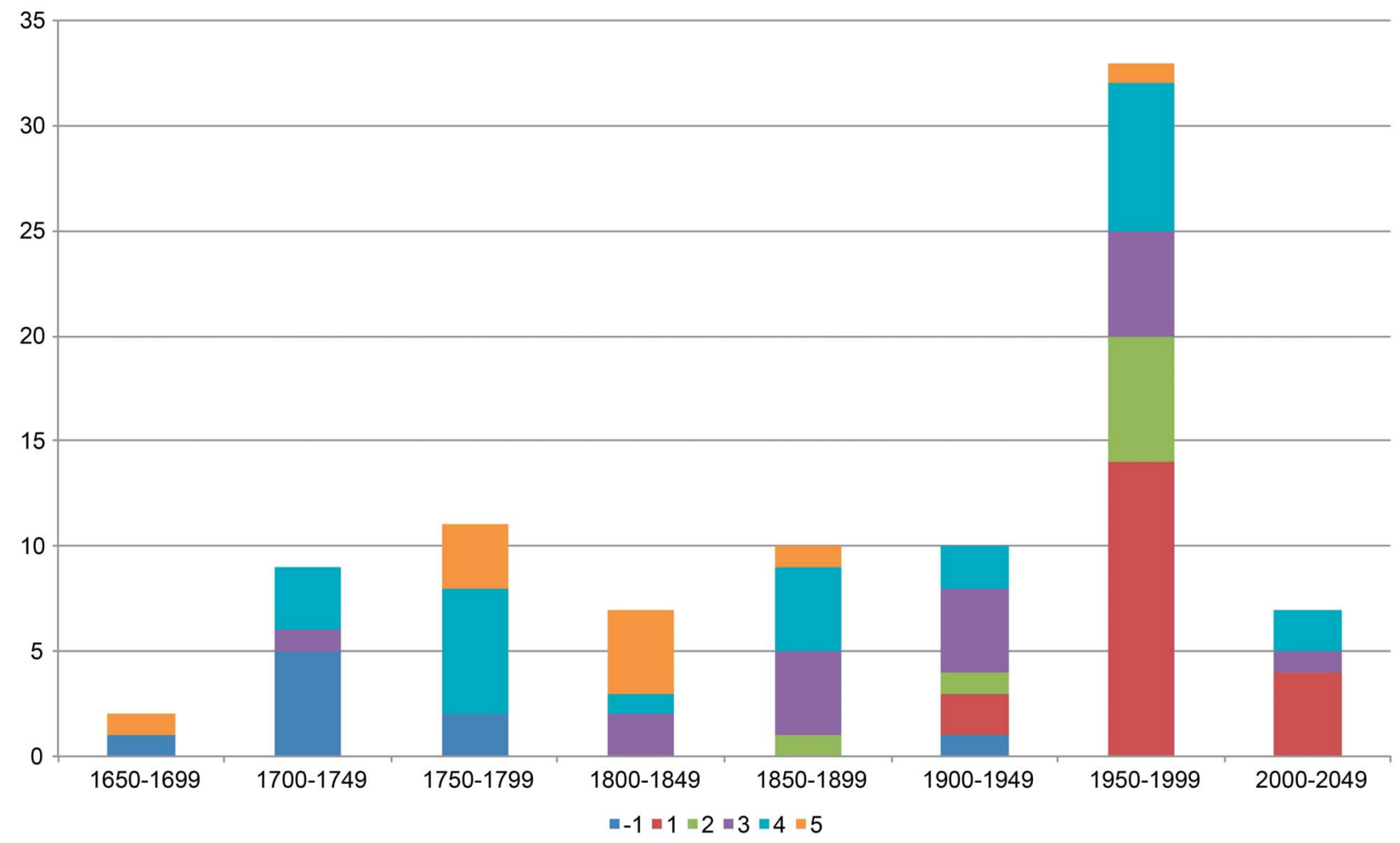

Figure 4. Distribution by period of 50 years and by category (from 1 to 5 ) of the SSHWS in Mascarene islands. The category1 (blue color) indicates a historic event mentioned in archives but insufficiently informed to be estimated by means of the SSHWS. 
lack of sufficient research. With the exception of the Maldives, the chapter "Case Studies" focuses instead on the Pacific and the Caribbean. Mark Pelling and Juha I. Uitto follow a more dynamic approach by questioning the factors that make these islands so vulnerable to natural disasters [12]. Following their investigation, they conclude that their vulnerability results essentially from limited mitigation capabilities and their limited integration into the global economy. More recently, other studies recommend reducing the impact of climate change and extremes of these small islands by a better transfer of technologies for adaptation and mitigation [13]. Facing these issues and recommendations present a big challenge to the global economy which is currently already struggling, so interrogating the archives is a relevant new resource as they deliver multiple historical experiences of adaptation which may be helpful for the present and the future.

\subsection{The Semantic Precondition}

\subsubsection{A Transdisciplinary Stake}

In recent years, under the influence of the social sciences the scientific community has been introduced to the key terms of vulnerability, exposure and resilience. The IPPC appropriated these terms and now employs them regularly. Their social significance is so strategic in the debate on global change it was thought necessary to define them in the IPCC-SREX-report. Fairly systematically used in environmental discourse, these terms are not necessarily well understood and defined by scientists and citizens. Indeed, the meaning of these words is different according to whether they are used by a researcher or climatologist, geographer, ecologist or economist. "Vulnerability" identified in the IPCC-SREX-report is thus presented as "the propensity or predisposition to be affected by a threat", without any more precision than that. The definition is so vague as to make its use not necessarily valid based on the data available. However, the definition of adaptation is more accurate as it relates to environmental realities paradoxically, social and cultural might be corrupted. Given these uncertainties and the lexical content of particular historical archives, it is necessary to first undertake a semantic exercise in order to best match the objects mentioned in historical records (hurricane, storm, vulnerability) with the expectations of the current scientific community. This methodological precaution is a condition of dialogue between the disciplines involved in the debate on climate change and the necessary step to a lasting collaboration between the exact sciences and the social sciences.

\subsubsection{The Words of the Past and Their Contemporary Significance}

In his book on the transition from a disaster in a risk so- ciety, the sociologist Ulrich Beck contrasts a pre-modern society described as "traditional", to a "modern" society [14]. In the first case, the perception of risk is presented as non-existent, replaced by a social conviction: that threats result from natural and unpredictable disasters. To this collective fatalism, he contrasts the industrialized society, whose birth is placed as around 1840. For Beck, generating risk, industrialization finally allowed its definition and quantification by instrumental rationalization and scientific progress.

However, the reality apprehended in the archives about hurricanes strongly contradicts the idea of the total vulnerability of ancient societies. It reveals that the roots of the concept of risk can be found much further upstream. Dictionaries of the 17 th and 18 th centuries deliver a point of view much more pragmatic when they define risk as a "danger", a "great peril" [15], they immediately put two notions related to the fact that "exposure to risk" [16]. It appears in the historical record as a social uncertainty which should be prepared for by developing strategies of resilience. Historical definitions are relevant today as they introduce an approach based not on a variable (risk) but on a social reality that is vulnerability already defined centuries ago in terms of what "may be injured" (populations) and "destroyed" (infrastructure and housing). Historical depth allows us to understand the roots of vulnerability [17] in the Mascarene Islands and facilitates the understanding of the trajectories of vulnerability [18], an assumption according to vulnerability results from a double evolution of society and the natural environment over the centuries [19]. Use of analytical methods helps us apply historical experience to the present and the future.

A research dedicated to the history of cyclones in the Mascarene Islands also helps to solve the question of the old meteorological terms. They illustrate remarkably well the evolution and dissemination of weather knowledge in the Indian Ocean and the assessment of hurricane risk by the authorities. From 1666 until about the 1850s the British and French governments routinely used the term "hurricane" to denote a very high winds causing significant human and material losses. The French regularly used the word "houragan", spelled with an H. It disappears permanently in the archives after the First World War The first mention of French "cyclones" appears in 1868 in a report by the Governor who speaks about the center of a cyclone, a term borrowed from the British terminology. This loan can be explained by the proximity of Mauritius, which was British island since 1810. Indeed, the word cyclone was invented by the sea captain Anglo-Indian Henry Piddington (1797-1858) following an observation made on a ship offshore of Mauritius in February 1845 . Noticing that the ship caught up in a meteorological event made a trajectory in a circle, he com- 
pared the phenomenon with a snake winding in circle and is inspired by the Greek word kyklos (circle) to call it "cyclone" [20]. A new lexical evolution occurred in the 1930 s with the rise of the term "atmospheric depression" in administrative and weather reports. This was a milestone which reflected the scientific progress of Meteorological Sciences because it designated more exactly the circulation around a closed center of low pressure in tropical regions.

\subsection{The Historical Vulnerabilities}

\subsubsection{People}

Contrary to what one might think, it seems that hurricanes did not cause exceptional loss of life. In this regard, the archives remain unclear for the pre-revolutionary period (before 1800), while the following period provides some statistics. Generally, human losses from cyclones did not exceed fifty dead. However, this mortality rate had racial and social disparities. Unsurprisingly, the main victims were slaves working in the plantations or ports, while those located in cities were less vulnerable. After the abolition of slavery in Mauritius (British colony) in 1835, then in Reunion (French colony) in 1848, the inequality of the death rate became social. In addition to the black people, new Indian migrants (coolies) and Malagasy came to replace slaves in agriculture and "small white" (poor white people) were now the main victims of cyclones due to their precarious living conditions. Thus, the majority of them perished in the collapse of their homes or drowned because their neighborhoods were located in or near rivers and ravines that suddenly became disastrous torrents.

More than the cyclone itself it was its side effects that affected most people. In fact, by destroying or damaging crops and infrastructure, cyclones affected the operation of the island's economy. In addition, the destruction of warehouses in ports or in the villages, threatened crop supplies and thus the food security of the population. The 1770 s were particularly difficult for the people who underwent a series of cyclones which were level 5 on the SSHWS. However, in respect of La Réunion or Mauritius, the turning point was really in the years 1806-1808 when they suffered repeated and extremely violent hurricanes which destroyed practically all the coffee trees, clove trees and corn. During these three years, the price of corn rose sixfold because of the shortage which reigned in the Mascarene Islands. After the hurricane of 1832, the supply difficulties gave rise to a social protest against the French and British authorities in Reunion and Mauritius which were accused of incompetence and passivity. Reunion protesters stormed "out of the woods like wolves and subjected those to a colonial gale violent enough to send them join their destroyed cassava and bananas" [21], while a riot broke out in Port Louis during which the British Governor was insulted and threatened [22].

Another side effect of cyclones, the health risk was a major concern of the authorities from the second half of the 19th century, as they feared the problems of water pollution because of the destruction of pipelines and wells. In 1913, outbreaks of typhoid occurred in several towns on the island of Reunion in the isolated mountains after the destruction of roads and bridges. In an attempt to contain the disease, military doctors were sent as a matter of urgency to these villages on horses and donkeys. On the spot, they treated and distributed some bleach to the populations.

\subsubsection{Housing}

The destruction caused by cyclones in the housing varied widely depending on the quality of the building. That is the reason why huts lived in by the slaves and the poor people, constructed of wood and roofed with straw or palm leaves, represented the majority of the damaged houses. Mostly, they are uncovered, overturned or sucked up by the cyclone and thrown far off. A traditional component of the architecture of islands even today, the more substantial colonial houses constructed of wood and covered with shingles were less vulnerable even if they regularly suffered damage.

Graver for the resilience of the island societies, the destruction or damage of public buildings were always felt as a profound trauma, in particular when it concerned churches, city halls, schools and high schools which are places of power and sociability. Often built stone from 1740 , these buildings were the first to be reconstructed after a disaster with public money and donations.

\subsubsection{Agriculture}

Storm surges regularly caused floods and accumulation of pebbles and sand. In 1718, such an event led to the sealing of the estuary of the "River of Pebbles" (Réunion) and the agricultural devastation of part of the nearby coast. More systematically, cyclones disrupt agricultural production brutally and massively. Winds and floods which accompany them hit foodcrop production vital to the population such as corn, manioc, rice and potatoes. In fact, it is especially floodwaters which ravage fields by ripping up the crops or by causing them to rot. Nevertheless, these small family-run farms show themselves more resistant than the other more speculative commercial plantations of coffee and clove trees which, because of their size are more exposed to the wind. They decline more and more after the cyclone of 1844 for the benefit of the sugar cane, considered more resilient.

\subsubsection{Navigation}

The violent winds of cyclones engender grave cones- 
quences for the ships which navigate or which drop anchor in the ports of Port Louis and Saint-Denis. The strategic position of these islands for the British and the French until the 1850 s added to the vulnerability because the total or partial destruction of the fleet could arouse an attack of the enemy. In 1771, the English council of Bengal indicates in a report that the French fleet of Port Louis underwent very heavy losses after the passage of a cyclone of category 5 on the SSHWS. Ships were effecttively very exposed and it could take less than one hour for them to be wrecked in the port which welcomes them. In 1823, the officers of the French navy looked on powerless at the wreck of nine ships on the beach of SaintDenis. The loss of ships from the fishing and trade fleets was also supplemented by the loss of rowboats and other small boats which were sent to the Rodrigue islands to gather the tortoises consumed on Mauritius and Reunion.

\subsubsection{Infrastructure}

The major part of the damage caused to infrastructure was generally connected to the floods and to the torrents caused by the rains which accompany cyclones. Water cut roads and destroyed bridges provoking a break of the land communications and the isolation of populations for days, sometimes weeks or months. Roads and railroads were mostly taken by the flows of water and mud as in 1875 on Reunion where all the rivers of the island overflowed at the same time and interrupted the traffic between the capital Saint-Denis and the South of the colony. In the 19th century, the frequency of cyclones led to a deterioration in the situation. Roads barely had time to be repaired before they suffered new damage. The sugar industry was also very exposed to the floods and the wind. From its development in the 1820 s, the mentions in the archives of the destruction of sugar refineries and their steam pumps are more and more frequent, and this served to weaken an economy more and more dependent on its sugar exports. Tidal waves also weakened infrastructure by damaging port facilities. Waves repeatedly destroyed the dikes and piers of the port of Barrachois on La Reunion. Finally, new factors of vulnerability appear from 1870 with the technical progress of the industrial revolution. It quickly becomes apparent that the new telegraphic and electric networks have little resilience. The official reports about cyclones speak from now on about overturned posts or about flooded power stations. This progress, which also gave rise to new weaknesses, contributed to aggravate the concern of the population which has become used to a new quality of life. In 1921, the storm caused the break of the submarine cables and interrupted the connections between Mauritius, Mozambique and France.

\subsection{Adaptation and Forms of Resilience}

The terms of adaptation and resilience are anachronistic with regard to this historical research because they first appeared in the second half of the 20th century in the disciplines of the physics of materials and child psychiatry. In the 1970s, they were assimilated by the ecologists then by the climatologists only one decade ago. The IPCC-SREX-Report defines the latter as the ability of a system and its component parts to anticipate, absorb, accommodate, or recover from the effects of a hazardous event in a timely and efficient manner. Whereas adaptation corresponds in the glossary to the process of adjustment to moderate the negative effects of the climate or to take advantage of it. In these conditions, we can wonder about the relevance of such terms from a historical point of view. In reality, ancient societies were not content with passively suffering the negative effects of the climate and in the Mascarenes Islands, the populations learnt to live with cyclones very early on and actively tried to limit their dangers.

\subsubsection{Individual Behavior}

The historical testimonies evoke original behavior which is always usual by the inhabitants. In 1666, inhabitants take refuge in the nearby forests to shelter from the wind but also from the risk of surge. Others leave their houses on the coast and find shelter in the hills and mountains where they wait for the end of the extreme event. In 1771, the fishermen identify the risk of cyclone by observing the foam of the sea, the sky. They pull their dugouts and their boats far from the sea. Meanwhile, the owners strengthen their houses by attaching ropes to them and by nailing boards on doors and windows.

At the end of the 18th century, the inhabitants noticed that the colonial houses were particularly exposed to the damage and the widespread use of wooden shingles to roof their houses instead of palm leaves and straw began. The municipal authorities even published regulations from 1786 which made the use of this construction material compulsory, which also helped to limit fire risk in the city.

\subsubsection{The Agricultural Revolution of the Sugar Cane} The series of disastrous cyclones of 1806 and 1807 plays a major role in the agricultural mutation of the Mauritius and La Réunion islands. After the cyclones of February and March, 1806 then those of 1807, planters and farmers gave up reconstituting the plantations of coffee and spices which were very badly damaged by winds and floods. They were largely replaced by the cultivation of sugar cane which was considered more resistant to the winds. The incidence of cyclones on the cultivation of the cane depends essentially on the rhythms of the plant. As a agronomist reminds us in 1884, the plant bears the storm well when it has only 6 to 8 months growth [23]. On the other hand, if the cyclone occurs a few months 
away from the harvest, the cane is eradicated or broken. Indeed, reports drafted after the passage of cyclones always insist on the biggest resilience of sugar canes compared with other crops. Besides, Great Britain and France were then at war and it become vital to produce sugar in colonies. So, the outbreak of cyclones and their escalation contributed with economic interests to amplify a profound agricultural transformation which even today still characterizes the Mauritius and La Réunion islands to a lesser extent.

Figure 5 shows that despite of six cyclones of categories $3-4$, the production of sugar and the land area dedicated to it are little impacted by cyclones. The relative and short decline after the cyclone of 1863 until 1864 is attributable in the appearance of the Borer insect (Chilo sacchariphagus), which lives as a parasite on some sugar cane and destroyed part of the harvest in Mascarenes.

\subsubsection{The Collective Alarm Systems}

From the 18th century, archives reveal the existence of rudimentary but relatively effective alarm systems. In ports, the authorities launched the alert thanks to a code known by captains. It consisted of raising a flag and firing two cannon-shot in case of bad visibility. Immediately, ships cut their ropes and sail. The efficiency of the plan implies a good knowledge of the meteorological phenomenon in a period when measuring instruments were very rare or non-existent. For the inhabitants, the alert was given by the churches which rang their bells at the approach of the cyclone.

From 1820 , the political will to manage the risk better by an alarm system improved considerably with the widespread use of meteorological instruments. In $\mathrm{La}$ Réunion, the captain in charge of the port of Saint-Denis had a major role. From 1829 he used barometers which allowed him to plan the arrival of an atmospheric depression better and to estimate the severity so as to know which plan alerts he had to organize. In Mauritius, the British were very sensitive to the meteorological risk. They created the Royal Alfred Observatory whose first instrumental data were published in 1862. The task of forecasting the tracks of these tropical storms was one of the most important of the duties of the Royal Alfred Observatory; in the eyes of the layman it constituted its raison d'être: and indeed it was of great local importance, especially to the Railway and Harbour Departments [24].

This work was greatly facilitated by the receipt of daily weather telegrams from Rodrigues and Réunion during the cyclone season, while in other seasons it only served to exemplify an oft-quoted adage that "a little knowledge is a dangerous thing". The development of the means of communication facilitated the prevention cyclone damage. To strengthen the relations between the various islands, a project of submarine cable was voted

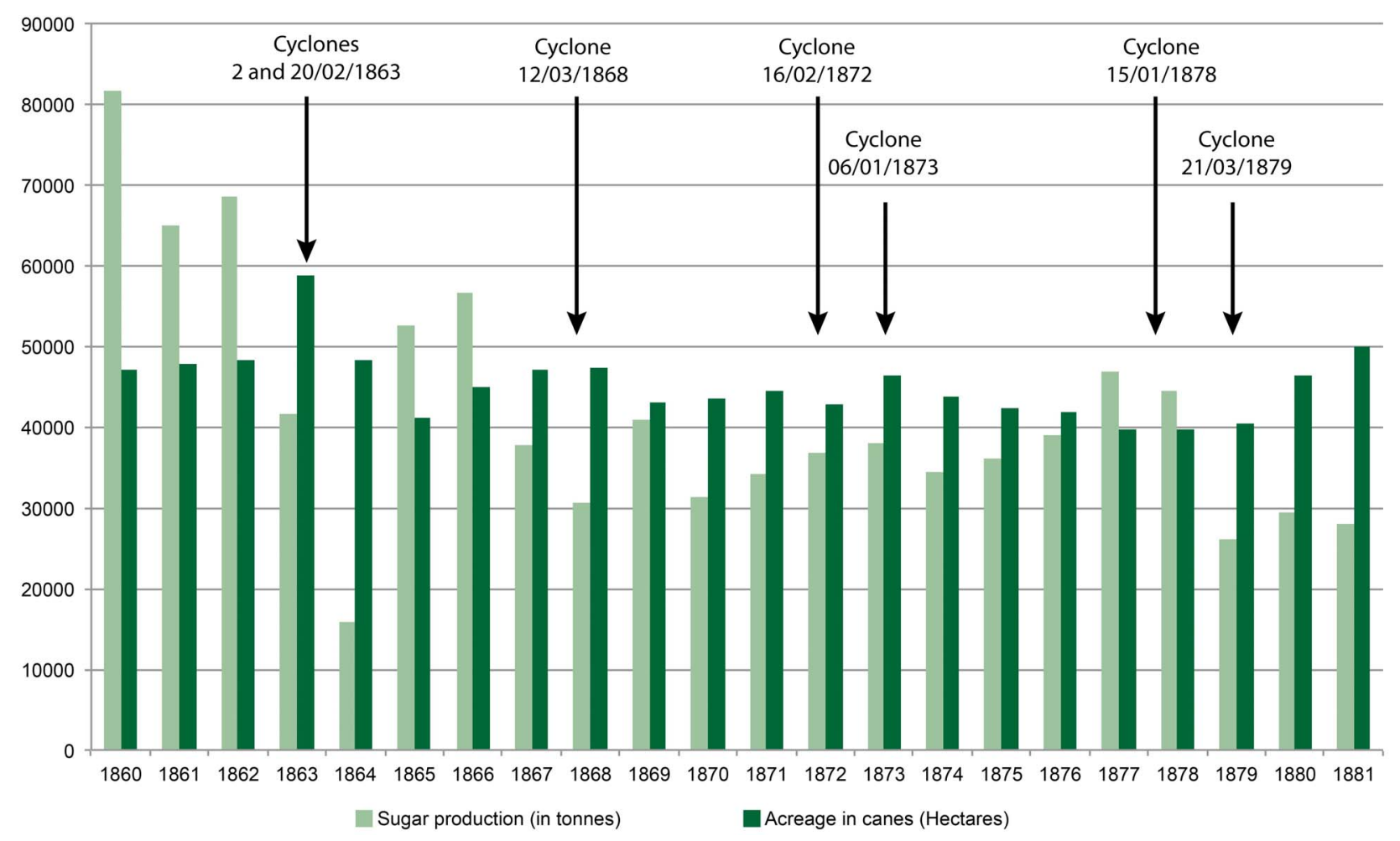

Figure 5. Production and surface of the sugar cane to La Réunion (1860-1881). Bars green-darkened indicate the production of sugar in ton and bars green-clear surfaces in hectares. 
by the French National Assembly in 1903. It consisted of connecting La Réunion to Madagascar and to Mauritius. Three years later, an agreement between Britain and France ratified this project of a submarine connection between La Réunion and Mauritius [25]. So, from the end of the 19th century a regional alarm system was built which connected the various islands of the Indian Ocean (Figure 6). The main observations were given by Tananarive and Port Louis. These two cities broadcast various bulletins mainly to Rodrigue, the Seychelles and La Réunion. The various ships present in the Indian Ocean also supplied numerous instrumental data to help plot the route of the cyclones.

Such cyclone warning systems were continuously developed and fine-tuned. Today, the governments of the region assert that the regional alarm system is a recent creation which is based on the recent collaboration between international organizations such as World Meteorological Organization (WMO) and Regional Specialized Meteorological Centre (Météo-France, La Réunion) [26]. The information exchange between them guarantees the announcement and the prevention of cyclones. It's the same for the three-tier warning system which according to them, was established in the 1950s, in particular by including police forces. In reality, the British and especially French authorities used the network of gendarmeries and police stations from the beginning of the 19th century with great effectiveness to warn then help the victims.

\section{Conclusions}

The historical method enriches the current debate concerning two strategic questions about global climate change. The first one is to know if the extreme events can be connected with climate change or not. The results presented in this historical research demonstrate that since the end of the 17th century, the chronology of cyclones in the Southern Indian Ocean underwent important fluctuations which were probably attributable to the natural cycles of the climate. On the other hand, archives of the time which were numerous and can be considered reliable prove that the trend in the number of cyclones is sharply upwards from 1800 and that from 1960 that trend

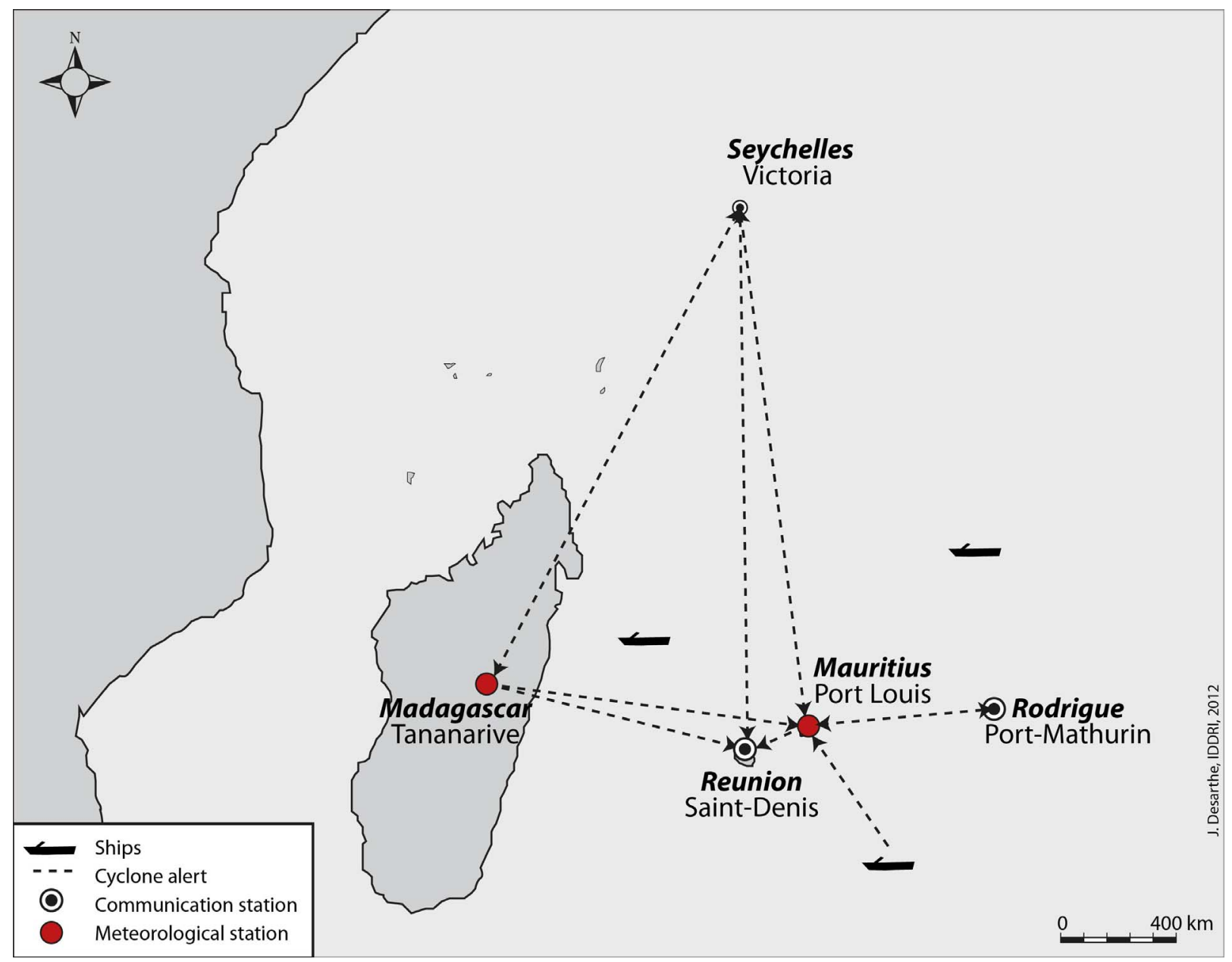

Figure 6. Regional network of alert and forecast against cyclones in the South of Indian Ocean by 1900. 
has increased dramatically. This observation thus strengthens, for the Indian Ocean at least, the thesis of a strong link between climate change and extreme meteorology. The other major stake in the current climatic debate, is the question of the resilience and the possibilities of adaptation offered to the increasingly exposed populations. Once again, historical experience enlightens the debate thanks to new and original data offering a strong social dimension. Yet, the awareness of the climatic risk by international public opinion, in particular on the particularly exposed Small Islands and the Least developed countries, depends very widely on the message delivered by the scientific community and the decision-makers.

In this respect, the historical information collected about the vulnerabilities and strategies developed by the old societies can be regarded as tools of dialogue allowing a more effective mediation. By showing the historical character of the climatic risk and by explaining how the populations tried to face the extreme events, history can also participate in the scientific debate about global climate change and contribute to our knowledge of what current societies can expect from it. The wealth of available material in archives worldwide indicates the possibility of multiple worldwide approaches but unfortunately, it will require long painstaking work to collect the data from archives which may in some cases be endangered for lack of interest on the part of the states or institutions which are the owners of the archives.

\section{Acknowledgements}

The article is partly result of three projects. The HEALTH project (Historic Extremes and heaLTH) is supported by the French Embassy of London, Churchill College, Cambridge and the Universities of Cambridge (Department of Geography) and Caen. The project "Climate and extreme climatic events in the last millennium" is funded by the Institut Universitaire de France. The VulneraRe project is financed by the Fondation Nationale de France. We are indebted to George Turner for proofreading our text.

\section{REFERENCES}

[1] IPCC, "Managing the Risks of Extreme Events and Disasters to Advance Climate Change Adaptation," Special Report of Intergovernmental Panel on Climate Change, Cambridge University Press, Cambridge, 2012, pp. 161163.

[2] A. Grinsted, J. C. Moore and S. Jevrejeva, "Homogenous Record of Atlantic Hurricane Surge Threat since 1923," Proceedings of the National Academy of Sciences, Vol. 109, No. 48, 2012, pp. 19513-19514.

[3] E. Garnier, "Les Dérangements du Temps. 500 ans de Chaud et de Froid en Europe," Plon, Paris, 2010.

[4] E. Garnier, N. Henry and J. Desarthe, "Visions Croisées de l'Historien et du Courtier en Reassurance sur les Submersions. Recrudescence de l'aléa ou vulnérabilisation croissante?" Quae, Paris, 2012, pp. 105-128.

[5] H. Chang-Hoi, K. Joo-Hong, J. Jee-Hoon, K. HyeongSeog and C. Deliang, "Variation of Tropical Cyclone Activity in the South Indian Ocean: El Nino-Southern Oscillation and Madden-Julian Oscillation Effects," Journal of Geophysical Research, Vol. 111, No. D22, 2006, p. 9. doi:10.1029/2006JD007289

[6] K. Hoarau, J. Bernard and L. Chalonge, "Review Intense Tropical Cyclone Activities in the Northern Indian Ocean," International Journal of Climatology, Vol. 32, No. 13, 2012, pp. 1935-1945. doi:10.1002/joc. 2406

[7] K. R. Knapp, M. C. Kruk, D. H. Levinson, H. J. Diamond and C. J. Neumann, "The International Best Track Archive for Climate Stewardship (IBTrrACS)," Bulletin of the American Meteorological Society, Vol. 91, No. 3, 2010, pp. 363-376. doi:10.1175/2009BAMS2755.1

[8] H. Dundas, "The History of Mauritius, or the Isle of France, and the Neighbouring Islands from Their First Discovery to the Present Time," Bulmer, London, 1801.

[9] H. Maurin and J. Lentge, "Le Mémorial de la Réunion," Vol. 1, Australes Éditions, Saint-Denis, 1979.

[10] H. S. Saffir, "Hurricane Wind and Storm Surge," The Military Engineer, Vol. 423, 1973, pp.4-5.

[11] R. H. Simpson, "The Hurricane Disaster Potential Scale," Weatherwise, Vol. 27, No. 169, 1974, pp. 169-186.

[12] M. Pelling and J. I. Uitto, "Small Island Developing States: Natural Disaster Vulnerability and Global Change," Environmental Hazards, Vol. 3, No. 2, 2001, pp. 49-62.

[13] De Comarmond and R. Payet, "Small Island Developing States: Incubators of Innovative Adaptation and Sustainable Technologies?" In: M. David and A. Pandya, Eds., Coastal Zones and Climate Change, 2010, pp. 51-68.

[14] U. Beck, "Risk Society: Towards a New Modernity," Sage, Londres, 1992.

[15] Furetière, "Dictionnaire Universel Contenant Généralement Tous les Mots Français," Arnout et Reiner, Leers, La Haye and Rotterdam, 1694.

[16] "Dictionnaire Universel Français et Latin Vulgairement Appelé Dictionnaire de Trévoux," Compagnie des Libraires Associés, Paris, 1704.

[17] P. T. Blaikie, I. Cannon and B. D. Wisner, "At Risk: Natural Hazards, People's Vulnerability and Disaster," Routledge, London, 1994.

[18] Magnan, "La Vulnérabilité des Territoires Littoraux au Changement Climatique: Mise au Point Conceptuelle et Facteurs d'Influence," Vol. 1, Analyse Iddri SciencesPo, 2009.

[19] Magnan, V. Duvat and E. Garnier, "Reconstituer les Trajectoires de Vulnérabilité Pour Penser Différemment l'Adaptation au Changement Climatique," Natures Sciences Sociétés, Vol. 20, No. 20, 2012, pp. 82-91.

[20] H. Piddington, "The Horn-Book for the Law of Storms for the Indian and China Seas," Bishop's College Press, Calcutta, 1844.

[21] N. Dodille, “Journal d'Un Colon de l'Île Bourbon," 
L'Harmattan, Paris, 1990.

[22] J. Jeremie and J. Reddie, "A Pamphlet. Recent Events at Mauritius," Hatchard and Son, London, 1835.

[23] A. Delteil, "La Canne à Sucre," Chalamel, Paris, 1884.

[24] A. Walter, "The Sugar Industry of Mauritius. A Study in Correlation. Including a Scheme of Insurance of the Cane Crop against Damage Caused by Cyclones," Arthur L.

\section{Manuscript Sources}

Archives Départementales de la Réunion, Séries C, 11 C, $20 \mathrm{C}$ et $22 \mathrm{C}$.

Archives Départementales de la Réunion, Série 2 C

Archives Départementales de la Réunion, Série M
Humphreys, London, 1910.

[25] "Bulletin des lois de la République Française," Vol. 68 and 72, Imprimerie Nationale, Paris, 1904 and 1906.

[26] “Managing Tropical Cyclones: Mauritius," Mauritius Meteorological Services, Vol. 12, United Nations Office for South-South Cooperation, 2011.
(Administration Coloniale), 1 M 4076-4087

The National Archives, IOR/F/4/588/14256

The National Archives, PRO 30/43

The National Archives, CO 1069/746 